\title{
The Large-eddy Observatory Voitsumra Experiment 2019 (LOVE19) with high-resolution, spatially-distributed observations of air temperature, wind speed, and wind direction from fiber-optic distributed sensing, towers, and ground-based remote sensing
}

\author{
Karl Lapo ${ }^{1,2}$, Anita Freundorfer ${ }^{1}$, Antonia Fritz ${ }^{1,3}$, Johann Schneider ${ }^{1}$, Johannes Olesch ${ }^{1}$, \\ Wolfgang Babel ${ }^{1,2}$, and Christoph K. Thomas ${ }^{1,2}$ \\ ${ }^{1}$ University of Bayreuth, Micrometeorology Group, Bayreuth, Germany \\ ${ }^{2}$ Bayreuth Center of Ecology and Environmental Research, BayCEER, Bayreuth, Germany \\ ${ }^{3}$ now at: University of Innsbruck, Innsbruck, Austria
}

Correspondence: Karl Lapo (karl.lapo@uni-bayreuth.de)

\begin{abstract}
.
The weak-wind Stable Boundary Layer (wwSBL) is poorly described by theory and breaks basic assumptions necessary for observations of turbulence. Understanding the wwSBL requires distributed observations capable of separating between submeso and turbulent scales. To this end, we present the Large Eddy Observatory, Voitsumra Experiment 2019 (LOVE19)

5 which featured $1350 \mathrm{~m}$ of fiber optic distributed sensing (FODS) of air temperature and wind speed, as well as an experimental wind direction method, at scales as fine as $1 \mathrm{~s}$ and $0.127 \mathrm{~m}$ in addition to a suite of point observations of turbulence and groundbased remote sensing. Additionally, flights with a fiber optic cable attached to a tethered balloon provide an unprecedented detailed view of the boundary layer structure with a resolution of $0.254 \mathrm{~m}$ and 10 s between $1-200 \mathrm{~m}$ height. Two examples are provided demonstrating the unique capabilities of the LOVE19 data for examining boundary layer processes: 1) FODS observations between $1 \mathrm{~m}$ and $200 \mathrm{~m}$ height during a period of gravity waves propagating across the entire boundary layer and 2) tracking a near-surface, transient submeso structure that causes an intermittent burst of turbulence. All data can be accessed at Zenodo through the DOI 10.5281/zenodo.4312976 (Lapo et al., 2020a).
\end{abstract}

\section{Introduction}

The atmospheric boundary layer, coined the "critical zone" (Brantley et al., 2007), is where heat, water vapor, carbon dioxide, pollutants, among other constituents are mixed between the atmosphere, biosphere, and hydrosphere. As such, this thin layer of the atmosphere and its coupling to the surface plays an important role for humans and ecosystems. However, there is a disparity between the actual boundary layer and the theoretical understanding during periods with weaker winds and statically 
https://doi.org/10.5194/essd-2020-392

Preprint. Discussion started: 19 February 2021

(c) Author(s) 2021. CC BY 4.0 License.

\section{(c) (i)}

stable conditions, which we refer to as the weak-wind Stable Boundary Layer (wwSBL). This categorization of the SBL largely overlaps with the other categorizations, such as very stable boundary layer (vSBL). During the wwSBL, turbulence can range from small, but finite mixing to large, intermittent bursts of turbulence. In both cases turbulence does not have a strong relationship to local variables and is therefore poorly described by similarity theory (Sun et al., 2012, 2020; Pfister et al., 2020a). While some aspects of the transition between these two states are understood (e.g., Van de Wiel et al., 2017) the drivers remain largely unknown (Abraham and Monahan, 2020; Acevedo et al., 2014; Mahrt et al., 2020). Further complicating our understanding of the wwSBL, assumptions necessary to invoke when observing atmospheric turbulence, for instance Taylor's hypothesis of frozen turbulence, are not valid (Sun et al., 2015; Mahrt et al., 2009; Pfister et al., 2019).

A growing body of evidence suggests that submeso-scale atmospheric structures play a substantial role in the turbulence generation of the wwSBL. Submeso-scale atmospheric structures are loosely defined as structures larger than turbulent eddies but shorter than the mesoscale, typically taken as greater than $10 \mathrm{~m}$ and up to kilometers with time scales between $20 \mathrm{~s}$ and an hour (Thomas, 2011; Thomas et al., 2012; Zeeman et al., 2015; Pfister et al., 2020b; Mahrt et al., 2009; Mahrt, 2010; Abraham and Monahan, 2020; Mahrt et al., 2020). These structures have been shown to include a diverse range of phenomena including internal waves (Sun et al., 2015; Cava et al., 2016, 2019; Petenko et al., 2019), solitary motions (Kang et al., 2015), horizontal wind direction meandering (Cava et al., 2016, 2019; Lang et al., 2018), semi-stationary thermal submeso fronts (Mahrt, 2017; Pfister et al., 2020b, a; Kang et al., 2015), and transient cold-air motions (Thomas et al., 2012; Zeeman et al., 2015) often with these phenomena co-occurring. Generally, little is known about the specific properties and drivers of these structures since they occur at a gap in our observational capabilities, especially near the surface (Pfister et al., 2020b, a; Mahrt et al., 2020; Acevedo et al., 2014; Zeeman et al., 2015; Thomas, 2011; Abraham and Monahan, 2020). As these structures are hypothesized to play an important role in the physics of the wwSBL and understanding their characteristics, driving factors, and influence on turbulence is a major goal of boundary layer research Sun et al. (2015).

Using the next generation of surface meteorological observational techniques that are specifically aimed at observing submeso-scale structures and their role in the wwSBL (Thomas et al., 2012; Zeeman et al., 2015), the European Research Council Horizons 2020 project 'DarkMix' seeks to reveal this 'dark side' of turbulence and submeso structures. One of the key needs for studying submeso-motions and their impact on turbulence in the wwSBL is spatially-distributed observations of atmospheric properties with a fine enough spatial and temporal resolution to separate between the submeso and turbulent scales and with a large enough spatial extent to resolve submeso modes (e.g., Abraham and Monahan, 2020; Pfister et al., 2020b, a; Mahrt et al., 2009). To that end, the Large-eddy Observatory - Voitsumra Experiment 2019 (LOVE19) featured a large array of fiber-optic distributed temperature sensing (DTS). This technique relies on the temperature-dependent inelastic Raman-backscatter from laser pulses transmitted along a fiber optic cable in order to resolve temperature at a fine spatial (as small as $0.127 \mathrm{~m}$ ) and temporal (as fine as 1s) resolution (Selker et al., 2006; Tyler et al., 2009). DTS has been shown to be accurately resolve air temperature at scales fine enough to resolve the difference between turbulent and submeso scales (Thomas et al., 2012; Zeeman et al., 2015; Peltola et al., 2020; Thomas, C.K. and Selker, 2021). It has also been developed to observe additional atmospheric properties on a distributed basis such solar radiation (Petrides et al., 2011), dew point (Euser et al., 2014; Schilperoort et al., 2018), wind speed (Sayde et al., 2015; van Ramshorst et al., 2020; Pfister et al., 2019), and recently 
wind direction (Lapo et al., 2020b). We refer to this broader family of sensing techniques as Fiber Optic Distributed Sensing (FODS, Thomas, C.K. and Selker, 2021).

The scientific goal of LOVE19 was to observe submeso-scale structures and their role in generating turbulence during the wwSBL. FODS observations were set-up in a configuration intended to capture submeso-scale structures as they flow across the study area in order to provide a spatial context for more typical boundary layer observations such as point and profile observations on towers and ground-based acoustic and light remote sensing. The experiment featured FODS air temperature, wind speed, and wind direction totalling 1.35km of fiber-optic observations. LOVE19 was coined a "Large Eddy Observatory" as it observed spatially-distributed boundary layer properties at spatiotemporal scales similar to those represented by the Large Eddy Simulation (LES) technique.

LOVE19 was also intended to be a test bed for improvements to various FODS techniques, building towards the eventual goal of a spatially-continuous fully-3D flow sensing technique. These improvements include a first demonstration of the FODS wind direction technique in an environmental application and the second-ever FODS wind speed deployment, including improvements to the technique such as vertically-oriented fibers and paired-fibers with identical radiative properties. Further, a tethered balloon was used to deploy a fiber-optic cable $200 \mathrm{~m}$ vertically in order to connect between observations of the surface layer and the remote sensing of the upper boundary layer with high resolution, spatially-distributed observations of air temperature.

The site description and layout, experimental description, and data availability are given in section 2. Ground-based remote sensing and flux observations are described in 3. Details of FODS operating principles as well as a description of the FODS components deployed during LOVE19 are presented in section 4. FODS wind speed and wind direction methods are discussed, and the FODS wind speed are evaluated in section 5. Finally, examples intended to highlight the novelty and merit of the LOVE19 data set for the broader atmospheric sciences community are presented (section 6). The first example demonstrates the unique observations from the deployment of FODS along a tethered balloon and tower (section 6.1). The second example examines a near surface, spatially discrete submeso-scale structure and its effect on turbulence (section 6.2).

\section{The LOVE19 campaign}

LOVE19 was deployed at the bottom of a broad valley in the Fichtelgebirge mountains in Germany $\left(50.0906^{\circ} \mathrm{N} 11.8543^{\circ}\right.$ E; $624 \mathrm{~m}$ asl; Fig. 1). The valley, which stretches from the southwest to the northeast, is surrounded by ridges up to $200 \mathrm{~m}$ tall to the north and up to $400 \mathrm{~m}$ tall to the south. It is open to the northeast, while being bound by a shallow saddle to the west. The dominant wind direction is along the valley, across the long axis of the study site (Fig. 1a). The site is characterized by intense cold-air drainage and pooling, exceptionally calm nocturnal winds, strong static stability, and horizontal wind direction meandering.

The experimental site was an agriculturally used perennial grass field approximately $200 \mathrm{~m}$ by $300 \mathrm{~m}$ in size. The general

land use in the valley was largely perennial short-statured grassland and agricultural fields as well as isolated forest patches. A few villages are scattered within a $5 \mathrm{~km}$ radius of the site. The site was situated at the bottom of a $40 \mathrm{~m}$ hill directly to the south. 


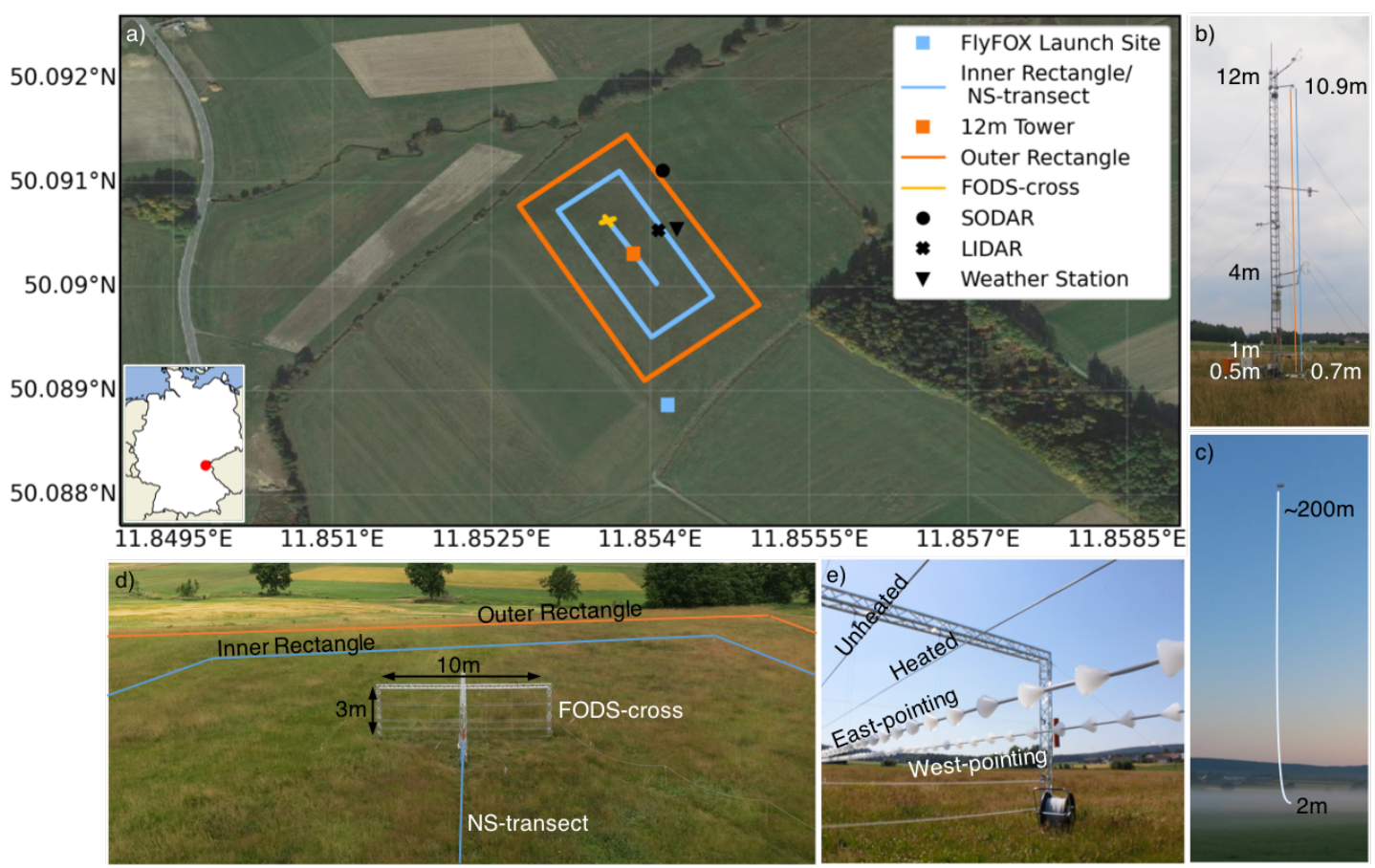

Figure 1. (a) A map of all components of the LOVE19 except for the ceilometer which was approximately 400m to the northeast (not shown). FODS components with active heating for wind speed are shown in orange (outer rectangle and the 12m tower), FODS components without heating are shown in blue (NS-transect and inner rectangle), and the FODS-cross is in gold. (b) The 12m tower with CSATs and the paired heated-unheated fiber optic cables viewed from the east. (c) FlyFOX on July 18, a morning with fog discussed in section 6.1, viewed from the top of the hill to the south. (d) The outer rectangle with paired heated-unheated fiber optic cables (orange), the inner rectangle (blue), FODS-cross (aluminum trussing), and the NS-transect as viewed from the top of the 12m tower. (e) The fiber quartet of the FODScross, consisting of paired heated-unheated and paired heated fibers with microstructures oriented in opposite directions are shown in more detail. To better highlight the fiber-optic cables they have been drawn onto images in b-d. Map data (C) 2021 Google, map imagery (C) 2021 GeoBasis-DE/BKG, GeoContent, and Maxar Technologies.

To the southeast lies an isolated patch of forest with a mean tree canopy height of $10 \mathrm{~m}$ while grass fields surround the field on all other sides, with a creek along the northern boundary. The experiment featured observations from ground-based remote sensing (section 3.1), an automatic weather station, a $12 \mathrm{~m}$ tower with four sonic anemometers (section 3.2 ), and up to $1350 \mathrm{~m}$ of DTS observations (section 4).

Observations during LOVE19 were collected between June 6 to August 14. This period can be subdivided into three phases according the availability of the FODS components (Fig. 2). No FODS observations were collected throughout June and the first half of July, although all other components were operational. Between July 15 and July 28 observations from FODS with active-heating elements were collected, specifically in the form of a FODS-cross (Fig. 1a,d,e), distributed wind speed and air temperature observations along the outer rectangle (Fig. 1a,d), and distributed wind speed along the $12 \mathrm{~m}$ tower (orange and 


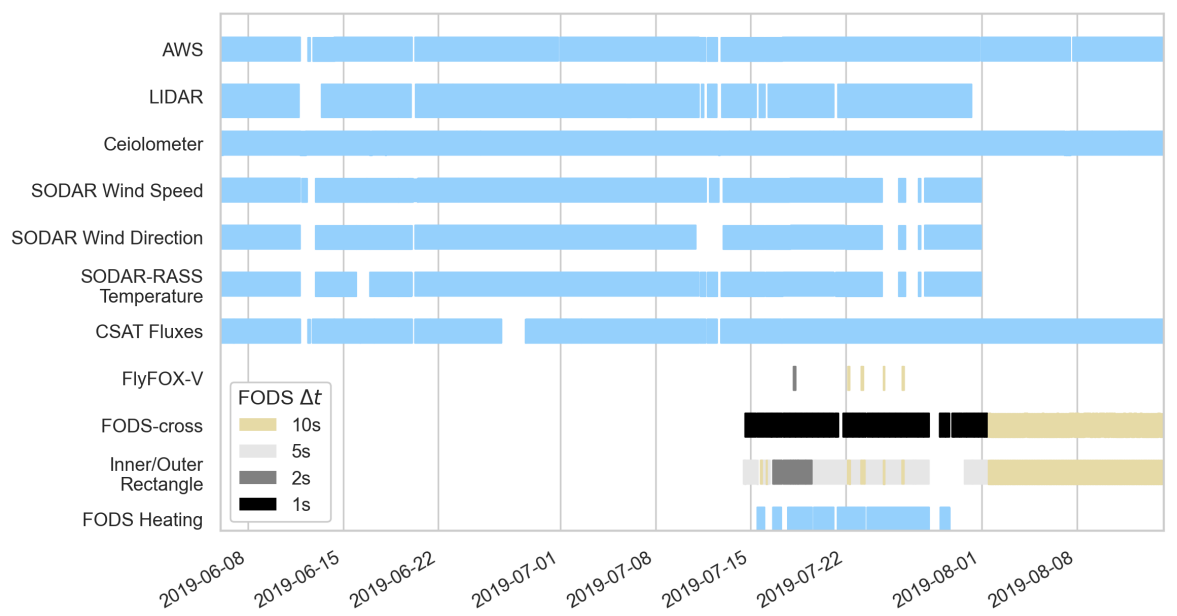

Figure 2. The data availability of the various observational systems during LOVE19. Specifically highlighted are the availability of the heating (necessary for FODS wind speed and direction) as well as the DTS instrument's temporal resolution, which varied with the campaign needs. Power failures occurred periodically due to electrical isolation issues heating the fiber optic cables (section 7).

gold components in Fig. 1a). On July 28 the active heating for FODS components was turned off decreasing the maintenance needs, as well as switching the DTS device from a high-resolution to a ruggedized lower-resolution unit (see section 4.1 for details).

\section{Ancillary observations}

In addition to the FODS components, LOVE19 included more typical boundary layer observations: point and profile observations of radiative and turbulent fluxes, air temperature, and horizontal wind speed and direction, as well as ground-based remote sensing. All observations were made within $40 \mathrm{~m}$ of each other except for the ceilometer which was located approximately $400 \mathrm{~m}$ to the northeast of the other observations.

\subsection{Ground-based Remote Sensing}

The ground-based remote sensing combined Sound Detection And Ranging (SODAR-RASS), wind LIght Detection And Ranging (LIDAR), and a ceilometer. The SODAR-RASS (Model DSDPA90.64 and 1.29 GHz RASS, Metek GmbH, Elmshorn, Germany) measured the Doppler-quantities horizontal wind speed and direction, and air temperature with a 10min temporal resolution, volume-integrated over $20 \mathrm{~m}$ vertical gates, in addition to non-Doppler acoustic backscatter intensity and vertical wind speed variance from spectral broadening (Thomas et al., 2006). The first physically meaningful observational gate center height was at $40 \mathrm{~m}$ above ground level (agl) and observations were available up to $300 \mathrm{~m}$ agl on average, while the exact maximum observation height varied with acoustic properties of the atmosphere and surrounding acoustic environment. 
https://doi.org/10.5194/essd-2020-392

Preprint. Discussion started: 19 February 2021

(c) Author(s) 2021. CC BY 4.0 License.

(c) (i)

The Doppler wind LiDAR (Model Stream Line, Halo Photonics Ltd., Worcester, UK) was deployed in the middle of the field site to minimize near-surface flow distortion by obstruction. The LIDAR was employed to detect the height of the atmospheric boundary layer, obtain snap shots of the three dimensional wind field, and observe vertical wind speed. Consequently, the LIDAR was operated in three modes: a conical Vertical Azimuth Display (VAD) scan, Range Height Indicator (RHI) scan, and a vertical stare (VST). The vertical stare was employed for 14 minutes starting at each full hour with alternating VAD and RHI scans of 1min duration between each VST. The constant zenith angle VAD scans enabled retrieval of the horizontal wind speed and direction following the method of Browning and Wexler (1968) every $30 \mathrm{~min}$ at a zenith angle of $60^{\circ}$ with eight (every $45^{\circ}$ ) steps in the azimuth angle. The constant azimuth angle RHI scans were used to retrieve a snapshot of the cross-valley wind field every half an hour. RHI scans were performed along an azimuth angle of $327^{\circ}$, chosen because of the lack of obstacles, with 37 steps of $5^{\circ}$ along the zenith. VSTs were performed for 14 minutes between the RHI and VAD scans, with a range gate of $24 \mathrm{~m}$ and a temporal resolution of $1 \mathrm{~s}$. The VST were aggregated to an $84 \mathrm{~s}$ time scale.

A ceilometer (Model CHM 8k, Lufft Mess- und Regeltechnik GmbH, Fellbach, Germany) was deployed to the northeast of the site as part of a new long-term flux observation site. The ceilometer measured the sky condition, cloud ceiling, total cloud coverage, and cloud penetration depths up to $8 \mathrm{~km}$ above the surface with a vertical resolution of $5 \mathrm{~m}$.

\subsection{Fluxes and ancillary observations}

Four sonic anemometers (CSAT3, Campbell scientific, Bremen, Germany) were located on the $12 \mathrm{~m}$ tower at heights of $0.5 \mathrm{~m}$, $1.24 \mathrm{~m}, 4.08 \mathrm{~m}$, and $11.99 \mathrm{~m}$ above the surface (Fig. 1a,b). Raw $20 \mathrm{~Hz}$ turbulence observations were processed with the flux eddy-covariance software 'bmmflux' (Thomas et al., 2009, see Fig. A1 for a schematic of the data flow). Fluxes and turbulent quantities were calculated using perturbation time scales of $1 \mathrm{~min}$ without any coordinate rotation and 10min and 60min with 3D rotation (Wilczak et al., 2001). The range of time scales enables using the sonic anemometer observations for different types of research questions, with the short $1 \mathrm{~min}$ scale specifically intended for use in separating between the turbulent- and submeso-scales following Mahrt and Thomas (2016).

An Automatic Weather Station (AWS) was situated 40m to the east of the tower. Air temperature and humidity at $2 \mathrm{~m}$ agl (Model HMP45A Thermohygrometer, Vaisala, Finland; radiation shielded and electricallly aspirated), horizontal wind speed and direction (Model wind vane and cup anemometer, Theodor Friedrichs and Co, Germany), and four component radiation (Model CNR4 Net Radiometer, Kipp and Zonen, The Netherlands). A soil temperature profile was observed at depths of $0.05 \mathrm{~m}$, $0.25 \mathrm{~m}$, and $0.5 \mathrm{~m}$ using platinum resistance (PT-100) temperature probes. Air temperature was also observed immediately above the surface at a height of $0.05 \mathrm{~m}$ agl using an unshielded PT-100 to record the minimum air temperature according to WMO standards. Finally, precipitation was observed at $1 \mathrm{~m}$ agl (OTT Pluvio ${ }^{2}$ - Weighing Rain Gauge, OTT HydroMet, Kempten, Germany). All observations were reported as $10 \mathrm{~min}$ block averages. 
https://doi.org/10.5194/essd-2020-392

Preprint. Discussion started: 19 February 2021

(c) Author(s) 2021. CC BY 4.0 License.

(c) (i)

\section{DTS}

Raman-spectra DTS uses the wavelength shifted backscattered photons from a laser fired along a fiber optic cable. Some of the backscattered photons have a higher and lower frequency, known as stokes and anti-stokes bands, with the ratio of these backscattered photons depending on the temperature of the fiber (e.g., Fig. 3a; Selker et al., 2006; Tyler et al., 2009). DTS can measure air temperature with sufficient temporal resolution to resolve turbulent fluxes (Thomas et al., 2012), turbulent thirdorder moments (Peltola et al., 2020), in addition to submeso-modes (Zeeman et al., 2015; Pfister et al., 2019, 2020b). In this experiment we employed a high-resolution Ultima DTS (ULTIMA DTS, Silixa, London, United Kingdom) capable of 1s and $0.127 \mathrm{~m}$ resolution as well as a lower resolution, ruggedized Silixa XT (XT-DTS, Silixa, London, United Kingdom) capable of $5 \mathrm{~s}$ and $0.254 \mathrm{~m}$ resolution.

For scientific applications it is necessary to continuously calibrate the DTS output (Hausner et al., 2011; van de Giesen et al., 2012; des Tombe et al., 2020) e.g. to transition from backscattered intensities to calibrated temperatures (Fig. 3a to 3b). For this reason the fiber-optic cable is run through reference sections with a known temperature. Typically, reference sections are water baths in which the fiber is loosely coiled with PT-100s observing the water temperature. However, water baths are difficult to maintain for long environmental deployments so instead two novel solid state reference baths were employed.

Each solid state reference bath consisted of a $20 \mathrm{~kg}$ cylinder of pure copper consisting of 4 interlocking parts, which allowed for an internal groove around which the fiber was wrapped. The temperature of each copper cylinder was controlled thermoeelectrically by Peltier elements to within $\pm 0.06 \mathrm{~K}$ and observed with a high-accuracy platinum resistance (PT-100) thermometer embedded within the copper body next to the fiber-optic cables. The walls of the internal groove containing the fiber-optic cables was painted with a high-emmissivity paint $(\epsilon=0.95)$ to eliminate any thermal differences across the solid state reference bath by enhancing the longwave radiative absorption and reemmission. Each solid state reference bath was housed in an insulated portable case to minimize temperature fluctuations in time and across the copper core. One solid state reference bath was cooled while the other was heated to target temperatures spanning the range of environmental temperatures observed within the fiber-optic array. All fiber-optic cables were routed through both solid state reference baths both at the beginning and end of each cable, yielding a total of four reference sections for each fiber (Fig. 3b).

The DTS devices were operated in a single-ended configuration and thus were calibrated using the single-ended full matrix inversion described in Hausner et al. (2011), utilizing three reference sections for calibration while withholding a reference section for validation and uncertainty analysis.

The last step in processing the DTS data is to convert from the instrument reported length along fiber (LAF) coordinates to the physical coordinates of the study array (e.g., the conversion from Fig. 3b to 3c). The process of mapping to physical coordinates has some uncertainty related to the LAF-step size, $\triangle \mathrm{LAF}$, and the instrument's ability to resolve steps in temperature. Temperature artifacts, such as from a fiber holder (Fig. 3b), propagate along the fiber some distance (Pfister et al., 2019). The exact mechanism is unclear but could include conducting heat along the fiber, over-saturation of the optical sensor inside the DTS instrument near sharp temperatures changes (Thomas et al., 2012), and wind artifacts from the cable holder sheltering the cable downstream. These artifacts, in combination with uncertainty in the exact location of a temperature perturbation from 

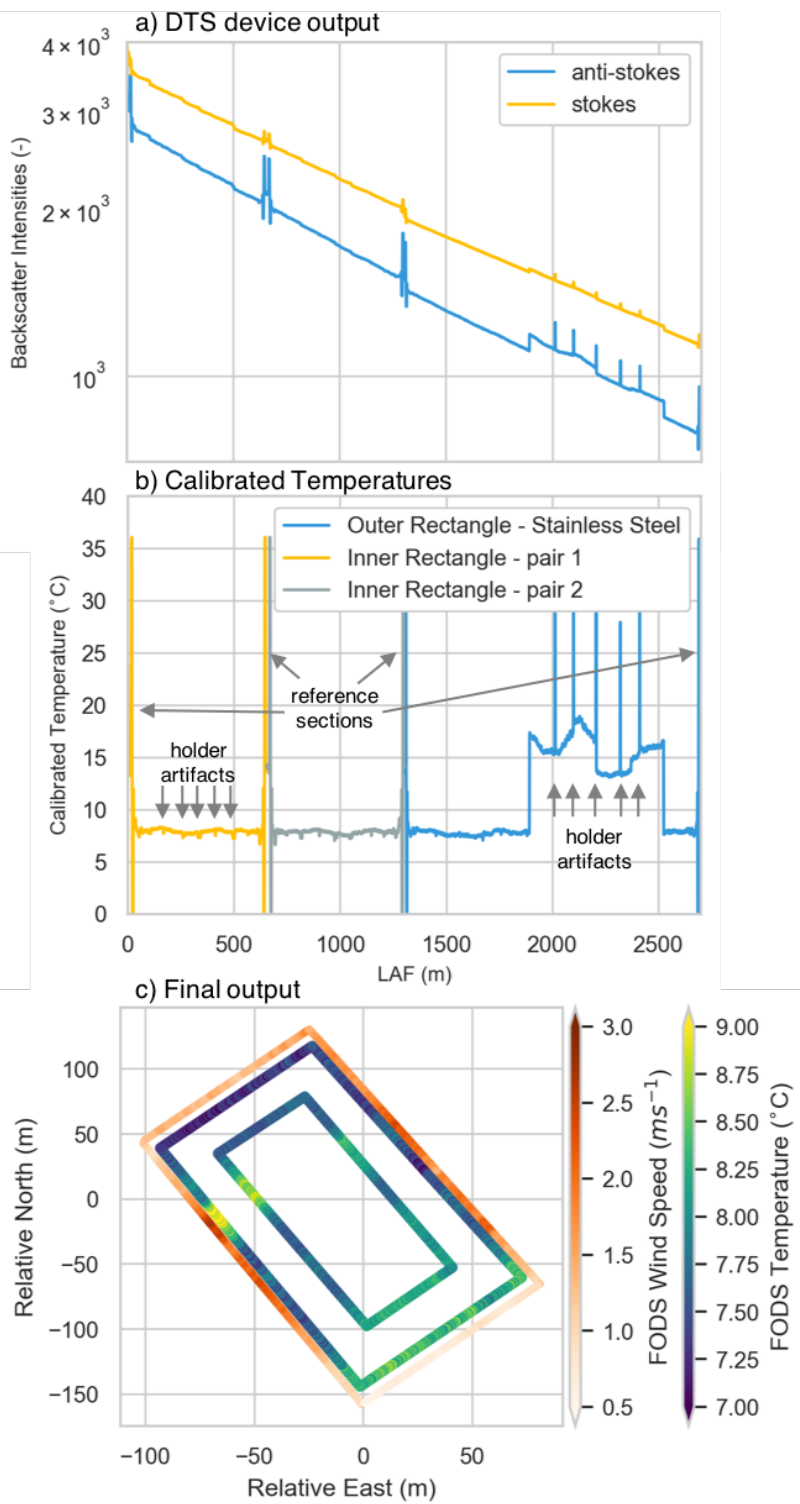

Figure 3. An example of the conversion of the DTS data from the (a) instrument reported stokes and anti-stokes backscatter intensities. (b) These intensities are calibrated following Hausner et al. (2011) using the reference sections. (a) and (b) share the x-coordinate, which is the instrument reported Length Along Fiber (LAF). The heated sections of the stainless steel fiber can be seen between 1900-2500 LAF. (c) The calibrated temperatures are mapped from LAF to physically-labeled locations with artifacts from the fiber holders removed and the wind speed perpendicular to the fiber derived from the temperature difference between the heated and unheated sections of fiber (section 5.1). The submeso feature seen in the (c) is analyzed in more detail in section 6.2 and Fig. 7 in order to highlight the utility and novelty of LOVE19. 
https://doi.org/10.5194/essd-2020-392

Preprint. Discussion started: 19 February 2021

(c) Author(s) 2021. CC BY 4.0 License.

the holders, creates an uncertainty in location of at least $\Delta \mathrm{LAF}$ with distances of $0.5 \mathrm{~m}$ being typical. For arrays on the order of kilometers, such as the inner and outer rectangle, we presume this uncertainty is negligible. However, the spatial uncertainty plays a stronger role in shorter sections of fiber, especially when aligning observations for paired fibers.

For FODS wind speed and wind direction (section 5) it is necessary to align sections and interpolate them to a common coordinate. The alignment of the cable-pairs was verified during periods without active heating (Fig. 2). The alignment is particularly critical for vertically-oriented deployments of paired cables, as the vertical gradients in temperature and wind speed make it such that even small a misalignment of size $\triangle L A F$ can degrade the derivation of e.g. wind speed. Fiber artifacts and alignment have been accounted for in the mapping of all DTS data from LOVE19 and all data are reported in a site-relative coordinate system. All steps from processing the original instrument output, calibration, mapping to physical coordinates, and aligning heated-unheated and coned sections were performed using pyfocs (version 0.5; Lapo and Freundorfer, 2020).

\subsection{Horizontal, Near Surface FODS arrays}

The near surface FODS array consists of two nested rectangles, inside of which was a $12 \mathrm{~m}$ tower with paired heated and unheated fibers, and an 80m unheated fiber transect running north to south (Fig. 1a,b,d). The outer rectangle fiber consisted of a $0.84 \mathrm{~mm}$ stainless steel cable with a $0.2 \mathrm{~mm}$ coating for electrical insulation (FIMT 0.84 SS316L with PE coating with $150 \mu \mathrm{m}$ multi-mode fiber, Solifos AG, Fiber Optic Systems, Windisch, Switzerland). The fiber weighed $3 \mathrm{~kg} \mathrm{~km}^{-1}$. The outer rectangle cable was looped such that the same fiber was deployed at two different heights, creating a pair of fibers offset by $0.15 \mathrm{~m}$. The upper stainless steel fiber pair (at 1.3m height agl) was resistively-heated (Model Heat Pulse System, Silixa, London, United Kingdom), facilitating the derivation of FODS wind speed along the outside of the LOVE19 domain (section 5.1). Due to the directional sensitivity of the FODS wind speed (Sayde et al., 2015; van Ramshorst et al., 2020), the outer rectangle effectively observes the east-west wind speed component along the long side of the rectangle and the north-south wind speed component along the short side. Heating was applied to the outer rectangle by forming a circuit with the heating unit consisting of four parallel sections approximately equal in length. As a result of slight differences in the length of the heated cable across the four sections, the heating rate $\left(\mathrm{Wm}^{-1}\right)$ varied around the outer rectangle. The estimated heating rates are included in Lapo et al. (2020a).

The inner rectangle consisted of a twisted pair of PVC cables (Twisted pair - two 900um SBJ with 50 $\mathrm{mm}$ MM fiber, AFL, Duncan, SC, USA) deployed at $1.3 \mathrm{~m}$ agl. The twisted pairs of cable were spliced together with the entire length of cable observed in a single-ended configuration, such that both twisted pairs observed the inner rectangle simultaneously (e.g., Fig. 3). However, in the single-ended configuration, there were unconstrained properties in the calibration, notably the differential attenuation between the stokes and anti-stokes photons. As a result, when comparing the observed temperature between the twisted pairs, there was an LAF-dependent bias ranging between $-0.12 \mathrm{~K}$ and $+0.29 \mathrm{~K}$ throughout the inner array. Consequently, Lapo et al. (2020a) only reports the first twisted pair, as it was less impacted by instrument noise.

The cables for the inner and outer rectangles were spliced together to form one long optical core approximately $2.8 \mathrm{~km}$ long. In the direction of the traveling laser light, the PVC fibers of the inner rectangle came first, followed by the the stainless steel 
https://doi.org/10.5194/essd-2020-392

Preprint. Discussion started: 19 February 2021

(c) Author(s) 2021. CC BY 4.0 License.

fiber, As a result, the observations of the outer rectangle have a larger uncertainty than those of the inner rectangle, as the DTS noise approximately doubles every kilfometer.

The combined inner- and outer rectangle fiber was observed using the XT DTS at a $5 \mathrm{~s}$ and $0.254 \mathrm{~m}$ resolution, except for between July 16 and July 19 when the high resolution ULTIMA DTS was employed. During the period with the higher temporal resolution, data were reported as a 1s average every 2s (Fig. 2).

Each cable was individually routed into the solid state reference sections such that they could be calibrated independently from each other. For each calibration a reference section was withheld for validation. Generally, the calibrated fiber-optic temperatures have biases slightly higher than published values (Fig. 4a,b). The noticeable deterioration of the validation between July 16 to July 19 can be partially explained by switching to the higher resolution instrument, as this reduced the number of temporal samples due to sampling two channels. However, the increased bias cannot be explained in this way. A possible explanation is that the higher resolution instruments generally perform worse in field conditions than the ruggedized, but lower resolution DTS devices.

All FODS array components were sampled by the lower resolution XT DTS on August 1 to reduce maintenance needs. As a result, the inner and outer rectangle temporal resolution became one 5 s average every 10 s, since the DTS device can only sample one fiber optic core at a time.

\subsection{FODS-cross}

The FODS-cross, NS-transect, and 12m tower (Fig. 1a,b,d,e), were observed using the high-resolution DTS instrument with a $1 \mathrm{~s}$ and $0.127 \mathrm{~m}$ sampling resolution. The fiber-optic cable was loosely buffered inside a high-resistance stainless steel sheath filled with gel (outer diameter $1.32 \mathrm{~mm}$, Model C-Tube, Brugg, Switzerland) and contained four optical cores, of which only the one with the shortest LAFs was used due to increasing instrument noise with longer LAF. The fiber-optic cable was coated by a $0.2 \mathrm{~mm}$ thick polyethylene (PE) jacket for electric insulation. The fiber weighed $5 \mathrm{~kg} \mathrm{~km}^{-1}$.

These FODS elements were observed in a single-ended configuration and calibrated as a single length of fiber. The calibrated temperatures for this component generally have more variability and slightly larger biases than the inner and outer rectangle (Fig. 4). The calibration also performed worse during the period when the inner and outer rectangle components were observed with the second higher-resolution Ultima DTS instrument. As stated above, the higher-resolution DTS devices appear to perform worse than the ruggedized, lower-resolution DTS during field conditions.

Within the FODS-cross (Fig. 1d,e), quartets of fibers consisting of a pair of fibers with small cones oriented in opposing direction, for observing wind direction, and paired heated and unheated fibers, for observing wind speed and air temperature, were strung within a rectangular frame. The paired fibers were horizontally separated by $15 \mathrm{~cm}$ (Fig. 1e). Orthogonal quartets of fiber were deployed at heights of approximately of $0.5 \mathrm{~m}$ (within the grass canopy), $1 \mathrm{~m}$, and $2 \mathrm{~m}$. Each section was vertically offset by $0.25 \mathrm{~m}$ from its orthogonal counter-part. The exact coordinates are included within Lapo et al. (2020a).

The FODS-cross was intended specifically as a test-bed and the first environmental deployment of the FODS of wind direction method. Preliminary lab work was able to successfully observe distributed wind direction in the one-dimensional flow of a wind tunnel (Lapo et al., 2020b). Based on the result from this preliminary work, PE cones were attached to the 
https://doi.org/10.5194/essd-2020-392

Preprint. Discussion started: 19 February 2021

(c) Author(s) 2021. CC BY 4.0 License.

(c) (1)
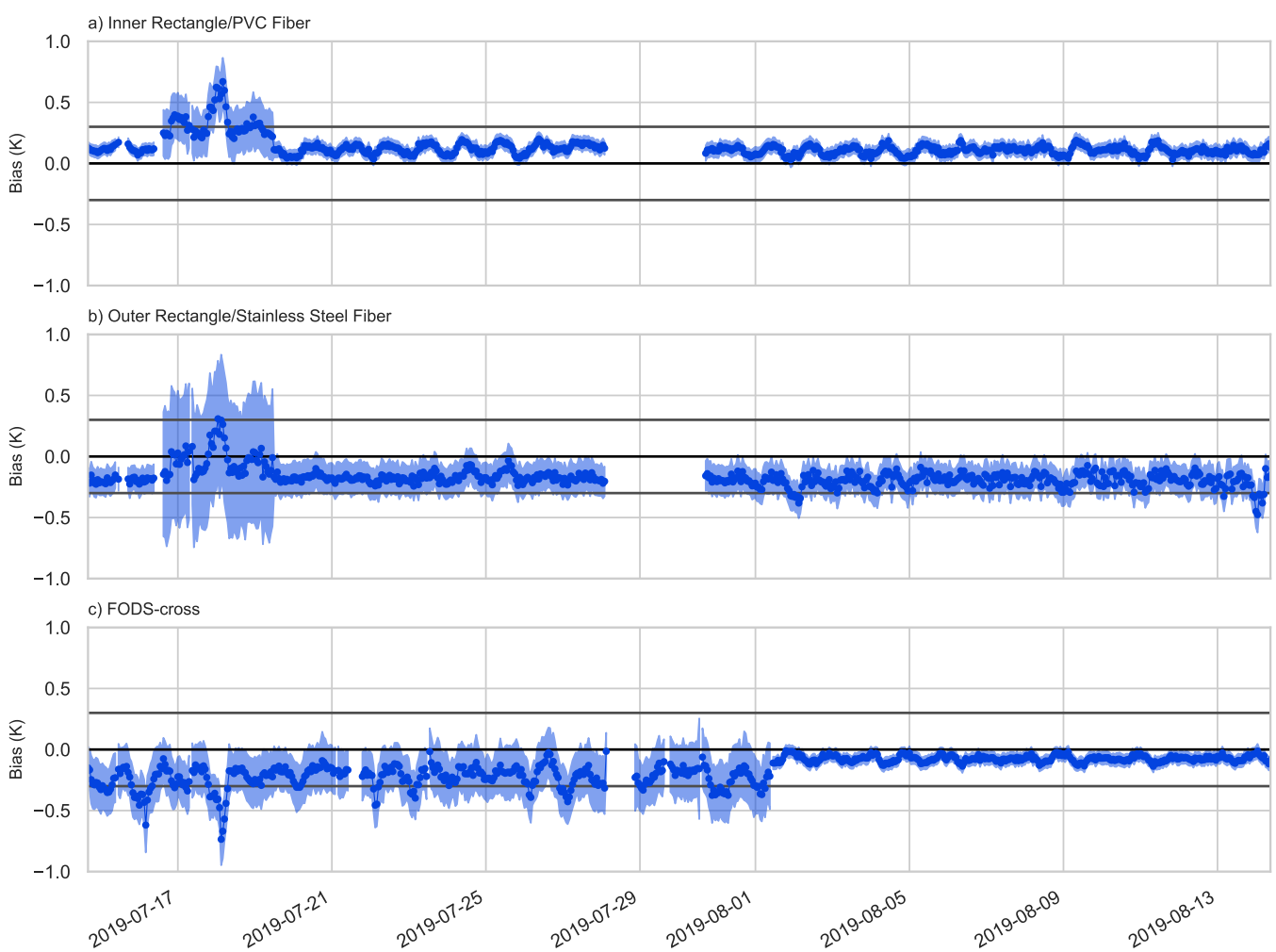

Figure 4. The bias in calibrated DTS temperatures relative to the reference PT-100 in the validation reference section. Biases are averaged over all spatial samples in the reference section and aggregated from the instrument time step to 1 hour. Solid lines are the mean bias and the shaded regions are the standard deviation of the bias within the hour. Bias time series are shown for (a) the inner rectangle, (b) the outer rectangle (both described in section 4.1), and (c) the FODS-cross (described in section 4.2). The thin horizontal grey lines at $0.3 \mathrm{~K}$ and $-0.3 \mathrm{~K}$ are provided as guidance for selecting higher quality data.

stainless steel fiber using injection molding. Cones were $12 \mathrm{~mm}$ in diameter and height with a $2 \mathrm{~cm}$ separation, consistent with the optimal cone construction determined by Lapo et al. (2020b).

\subsection{FLYFOX}

The Flying Fiber Optic eXperiments - Voitsumra (FlyFOX-V) were performed using a vertical deployment of the twisted-pair fiber attached to a tethered balloon on select mornings and evenings. These flights enabled observing air temperature between 
https://doi.org/10.5194/essd-2020-392

Preprint. Discussion started: 19 February 2021

(c) Author(s) 2021. CC BY 4.0 License.

(c) (i)

$2 \mathrm{~m}$ and $200 \mathrm{~m}$ above ground level (agl) (Fig. 1c) at a fine resolution (3s-10s and $0.127 \mathrm{~m}-0.254 \mathrm{~m}$ ), yielding an unprecedented level of observational detail of the structure of the weak-wind stable boundary layer.

The tethered FODS experiments were conducted with a twisted-pair of PVC fibers (Twisted pair - two 900um SBJ with 50um MMfiber, AFL, Duncan SC), observed in a single-ended configuration. The fibers were run through two reference water baths, one warm and one cold, both at the beginning and end of the length of fiber tethered to a balloon, allowing calibration following the same procedure as for the other FODS components. The reference water baths were monitored with waterproof temperature sensors (RBRsolo ${ }^{3}$ T, RBR, Ottawa, ON, Canada). Calibrated temperatures had a bias of $\approx 0.1 K$. This bias is higher than expected (Hausner et al., 2011), but may be explained given the length of fiber and the unconstrained effect of strain on the fiber at the top of the profile due to the single-ended calibration. Only the ascending twisted PVC fiber is presented due to the effect of a difference in the differential attenuation between the cable pairs.

A custom-designed tethersonde observing air temperature, relative humidity, and air pressure (Model BME280, Bosch sensortec $\mathrm{GmbH}$, Reutlingen, Germany) in addition to wind speed using a hot-wire anemometer (Model Rev C, Modern Device, Providence, USA) contained in a 3D-printed housing was deployed immediately below the tethered balloon, at the top of the FODS profile. Biases in the tethersonde pressure were removed by comparing to high-quality observations (Digiquartz Nano-Resolution Barometers Model 6000-16B, Paroscientific, Redmond, WA, USA) when the balloon was at the surface.

FlyFOX-V observed four morning transitions and one evening transition (Table 1). All flights except 18 July were observed with the lower-resolution XT DTS device. As the DTS device observed both the inner/outer rectangle as well as FlyFOX-V, the temporal resolution for both components was a $5 \mathrm{~s}$ temporal average every 10 s during the flights. The flight on 18 July was observed with a second high-resolution Ultima DTS device simultaneously with the outer/inner rectangle, yielding a temporal resolution of $1 \mathrm{~s}$ averages every $3 \mathrm{~s}$ and a $0.127 \mathrm{~m}$ spatial sampling resolution. All flights occurred on mornings with relatively little cloud cover and no fog except for 18 July (Table 1). This flight was characterized by low-lying fog (Fig. 6c). The sun rose locally on the launch area at $0450 \mathrm{Z}$ due to the effect of local shading from nearby topography and trees.

The DTS temperatures along the tethered balloon profile were converted from an LAF coordinate to a height coordinate, $z$, and from dry-bulb temperature to virtual potential temperature, $\theta_{v}$. An iterative solution to the hypsometric equation was employed using observations of pressure and relative humidity at the surface and the tethersonde as well as the DTS observations along tethered profile (Fritz et al., 2020).

$z=\frac{R \overline{T_{v}}}{g} \ln \left(\frac{p_{s f c}}{p(z)}\right)$

where $z$ is the height above the surface, $R$ is the specific gas constant for dry air, $\overline{T_{v}}$ is the mean virtual temperature between the surface and height $z, p_{s f c}$ is the pressure at the surface, and $p_{z}$ is the pressure at $z$. The height coordinate was linearly interpolated between the surface and the top of the profile. 
Table 1. Details for the FLYing Fiber Optic eXperiment - Voitsumra (FLYFOX-V).

\begin{tabular}{|c|c|c|c|}
\hline Flight & times & DTS device & Notes \\
\hline 18 July & 3:08Z-6:54Z & Ultima & $\begin{array}{l}\text { Fog during the first several hours of flight. Winds less } \\
\text { than } 2 \mathrm{~ms}^{-1} \text { within lowest } 150 \mathrm{~m} \text {. }\end{array}$ \\
\hline 22 July & $3: 18 Z-6: 10 Z$ & XT & $\begin{array}{l}\text { Relative humidity }>90 \% \text {, no fog, winds less than } \\
2 m s^{-1} \text { within lowest } 150 \mathrm{~m} \text {. Wind direction within SBL } \\
\text { southerly. Cloud cover between } \frac{5}{8} \text { to } \frac{7}{8} \text {. }\end{array}$ \\
\hline 23 July & 2:59Z-6:30Z & XT & $\begin{array}{l}\text { Relative humidity }>90 \% \text {, no fog, winds less than } \\
2 \mathrm{~ms}^{-1} \text { within lowest } 150 \mathrm{~m} \text {. Wind direction within SBL } \\
\text { southerly. }\end{array}$ \\
\hline 24 July & 18:13Z-19:55Z & XT & $\begin{array}{l}\text { Qualitatively higher wind speeds but SODAR observa- } \\
\text { tions were not available to verify, lower and more vari- } \\
\text { able balloon height. }\end{array}$ \\
\hline 26 July & 3:21Z-6:24Z & XT & $\begin{array}{l}\text { Relative humidity }>90 \% \text {, no fog, winds less than } \\
2 m s^{-1} \text { within lowest } 150 \mathrm{~m} \text {. Wind direction within SBL } \\
\text { northerly. }\end{array}$ \\
\hline
\end{tabular}

\section{Fiber Optic Distributed Sensing of Wind Speed and Direction}

Both the FODS wind speed and direction methods are based on the temperature difference between pairs of fibers. The data available in Lapo et al. (2020a) are only the calibrated temperatures. In both cases the decision to report calibrated temperatures instead of derived quantities enables users of the LOVE19 data to refine their own derivation of the quantity in question. For wind speed, refinements are possible but the wind speeds presented here can be trivially recovered using pyfocs (Lapo and Freundorfer, 2020) following the example scripts provided with Lapo et al. (2020a), whereas for FODS wind direction the method is still experimental and we anticipate that future research will continue to improve the technique.

\subsection{Wind Speed}

Distributed wind speed is observed using a pair of cables, with one of the cables resistively heated and the other cable unheated, effectively creating a distributed hot-wire anemometer (Sayde et al., 2015; van Ramshorst et al., 2020, S15 and vR20 respectively). The difference in temperature between the two fibers is a function of the wind speed orthogonal to the fiber. There are two versions of the FODS wind speed derivation. The original version from S15 is

$U_{N}=\frac{0.5 P \pi^{-1} r^{-1}+\left(S_{b}+S_{d}+\rho S_{t}\right)+\epsilon L_{i n}-\epsilon \sigma T_{s}^{4}+\frac{1}{2} c_{p} \rho \frac{d T}{d t}}{-C(2 r)^{(m-1)} \operatorname{Pr}^{n} \frac{P r}{P r_{s}}{ }^{1 / 4} K_{a} \nu^{-m}\left(T_{s}-T_{f}\right)}$

where $U_{N}$ is the wind speed orthogonal to the fiber pair, $P$ is the heating rate in $W m^{-1}, r$ is the fiber's outer radius, $S_{d}, S_{d}$, and $S_{t}$ are the direct, diffuse, and surface reflected shortwave respectively, $L_{i n}$ is the mean of the downwelling and upwelling 
longwave irradiances, $\epsilon$ is the fiber's emissivity, $T_{s}$ is the heated fiber's temperature, $c_{p}$ is the specific heat capacity of the fiber, $\rho$ is the fiber's density, $C, m$, and $n$ are flow dependent coefficients, $P r$ and $P r_{s}$ are the Prandtl numbers for air temperature and the heated fiber respectively, $K_{a}$ is the thermal conductivity of air, $\nu$ is the kinematic viscosity of air, and $T_{f}$ is the temperature of unheated fiber (i.e., air temperature). In LOVE19 we remove some of the complicating factors in FODS wind speed by using identical fibers, as in $\mathrm{vR} 20$, such that the shortwave irradiances drop out and the equation simplifies to

$U_{N}=\frac{0.5 P \pi^{-1} r^{-1}+\epsilon L_{i n}-\epsilon \sigma T_{s}^{4}+\frac{1}{2} c_{p} \rho \frac{d T}{d t}}{-C(2 r)^{(m-1)} P r^{n}{\frac{P r}{P r_{s}}}^{1 / 4} K_{a} \nu^{-m}\left(T_{s}-T_{f}\right)}$.

vR20 additionally suggest improvements to the representation of the convective heat transfer, yielding

$300 U_{N}=\frac{0.5 P \pi^{-1} r^{-1}+\epsilon L_{i n}-\epsilon \sigma T_{s}^{4}+\frac{1}{2} c_{p} \rho \frac{d T}{d t}}{-C(2 r)^{(m-1)} \operatorname{Pr}^{n} K_{a} \nu^{-m}\left(T_{s}-T_{f}\right)}$

with the values for $C, m$, and $n$ adjusted relative to $\mathrm{S} 15$. Both versions of the wind speed expression are available in pyfocs (Lapo and Freundorfer, 2020). All FODS wind speeds shown in this manuscript were derived following vR20.

As the vR20 and the vertically-oriented fibers have not been tested in an environmental application, the FODS wind speed along the $12 \mathrm{~m}$ tower were evaluated. In previous studies of FODS wind speed, care is taken to adjust the evaluation of FODS wind speed for the angle of attack (Pfister et al., 2019; Sayde et al., 2015; van Ramshorst et al., 2020). For the FODS wind speed along the $12 \mathrm{~m}$ tower, this complicating factor is not relevant. The vertical orientation of the cables removes the angular dependence for deriving the horizontal wind speed since the angle of attack of the near-surface flow deviates only a little from orthogonal due to the small time-averaged vertical wind speed.

The heating rate, $P$, was varied over a range of values in order to optimize wind speed along the $12 \mathrm{~m}$ tower for the period with heating, July 15 to July 28 (Fig. 2). The DTS bin nearest to the $1.25 \mathrm{~m}$ sonic anemometer was evaluated to yield a mean bias and to find the linear slope between the two observations (Fig. 5a-d). The evaluation was stratified according to a day (0700-1600) vs night (2000-0600) and cloudiness regime. Cloudiness regimes were defined using the ceilometer-derived cloud cover octets $\left(\frac{0}{8}-\frac{1}{8}\right.$ are clear, $\frac{2}{8}-\frac{6}{8}$ are partially cloudy, and $\frac{7}{8}-\frac{8}{8}$ are cloudy). All nighttime evaluations yield the same optimal heating rate of $4.5 \mathrm{Wm}^{-1}$ for FODS wind speed regardless of sky condition, only slightly higher than the observed heating rate of $4.3 \mathrm{Wm}^{-1}$. In contrast, the daytime evaluations indicate that sky condition affects the derivation of FODS wind speed, as seen by cloud cover-dependent optimal heating rates.

FODS wind speed during the daytime with cloudy weather tends to have more scatter and overestimate the wind speed relative to FODS wind speed during the day with clear conditions for the same heating rate (Fig. 5e,f). In S15, FODS wind speed tended to underestimate wind speed during stronger winds as a result of the heating rate not being strong enough to maintain a sufficiently large temperature difference between the heated and unheated fibers. Our observations did not confirm this finding, as the FODS wind speed overestimates stronger winds during cloudy conditions. A heating rate of $4.5 \mathrm{Wm}^{-1}$ is two times larger than the heating rate used in S15, suggesting that the saturation issue can be solved with sufficient heating of 
the fiber. Additionally, the difference in temperature between the heated and unheated fibers did not fall below $4.2 \mathrm{~K}$, with a mean value of $8 \mathrm{~K}$ and a maximum of $31 \mathrm{~K}$. These temperature differences are larger than those reported in either S15 or vR20.

The decreased performance of FODS wind speed during the day indicates the existence of radiation artifacts. The unheated fiber shows a clear heating from a radiation artifact during the day (not shown, Sigmund et al., 2017). As a result of this heating, the unheated fiber is not in equilibrium with the atmosphere and instead experiences its own convective heat loss, giving $T_{f}$ in equation 2 a small error that depends on wind speed. Additionally, radiative and flow obstacles can be seen when examining the entire FODS wind speed profile along the tower (Fig. 5i-1). During the day with clear skies, a deviation from the expected logarithmic wind speed profile occurs near $8 \mathrm{~m}$ agl, while at night an artifact appears around $4 \mathrm{~m}$. As a result of these artifacts, selecting an optimal heating rate according to the evaluation at $1.25 \mathrm{~m}$ creates biases up to $0.25 \mathrm{~ms}^{-1}$ when evaluating against the $4 \mathrm{~m}$ sonic anemometer for the same heating rate. Consequently, we suggest that the $12 \mathrm{~m}$ tower FODS wind speed cannot resolve vertical gradients less than this value. However, future refinements of the FODS wind speed expressions may be able to improve the wind speed computations.

\subsection{FODS wind direction}

The FODS-cross used orthogonal segments of coned and heated-unheated fiber pairs for the goal of fully resolving two dimensional atmospheric flow on a distributed basis. The FODS wind direction method is predicated on a similar argument as FODS wind direction. A pair of resistively-heated fibers with microstructure cones attached in opposing directions induce a convective heat loss that is sensitive to the wind direction along the fiber (Lapo et al., 2020b). As a result, the temperature difference between the coned-fiber pairs is related to wind direction. However, this approach has only been demonstrated in wind tunnel tests for one-dimensional flows along the fiber. We sought to refine the FODS wind direction technique for two-dimensional flows by taking advantage of the coned fibers with orthogonal orientation. LOVE19 was an environmental test bed for this approach and is the subject of future work.

\section{Examples of observed submeso-scale structures}

345 These data are intended to be used to study submeso-turbulence interactions in the wwSBL. We demonstrate two use cases for the LOVE19 data, specifically highlighting how the novel FODS data observed submeso-scale features which cannot be accomplished using traditional micrometeorological sensors and sensor networks. These examples are provided to help elucidate the utility of spatially-distributed observations. In the first example a column of vertical observations are presented to highlight how the FODS observations along the tower and FlyFOX-V fill in details missing from the ground-based remote sensing and tower observations (Fig. 6). In the second example, a near-surface submeso-scale structure is investigated which originates from outside of the study area and propagates across it (Fig. 7). The submeso-scale structure co-occurs with meandering of the horizontal wind direction and an intermittent burst of turbulence near the surface. 

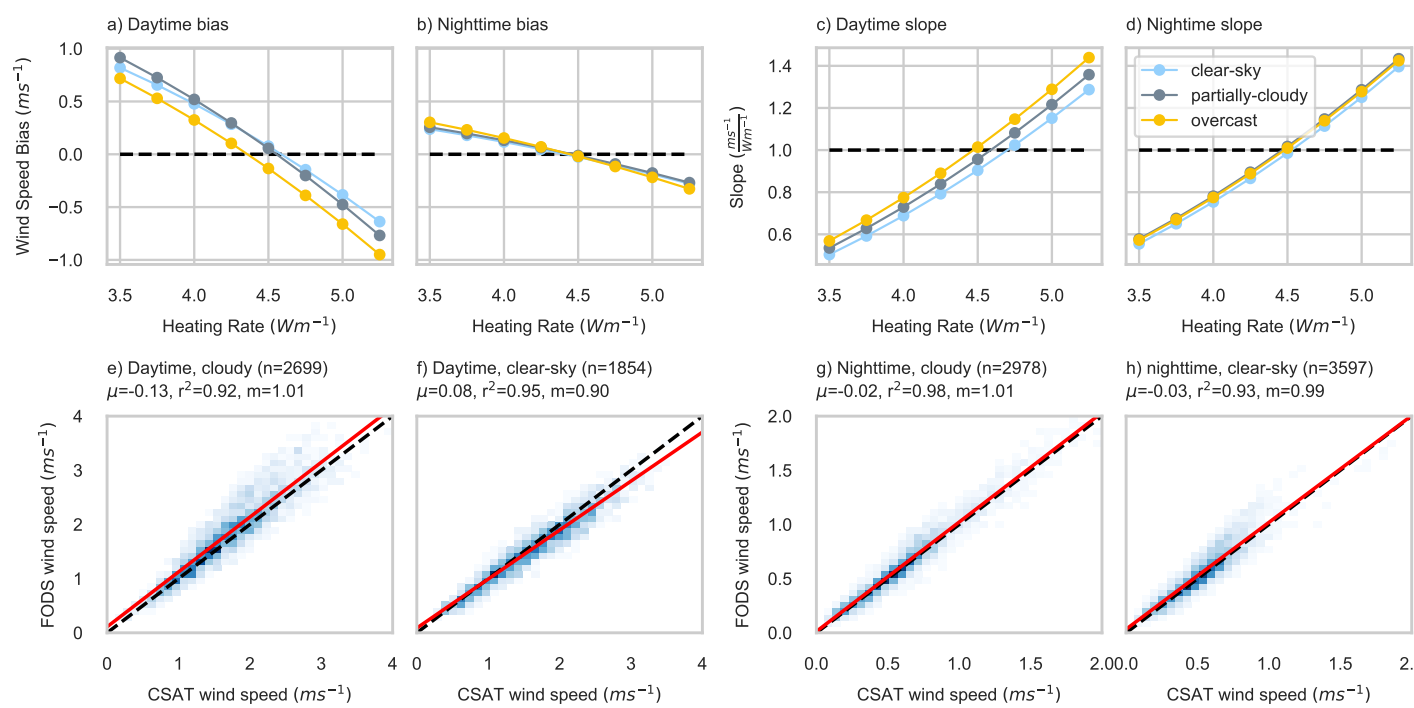

f) Daytime, clear-sky $(n=1854)$
$\mu=0.08, r^{2}=0.95, m=0.90$

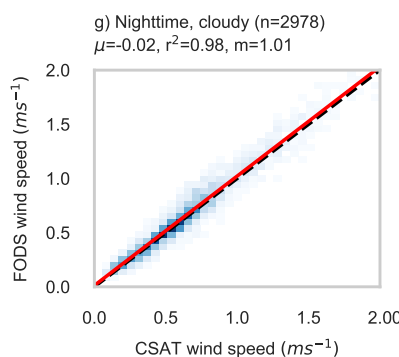

h) nighttime, clear-sky $(n=3597)$ $\mu=0.08, \mathrm{r}^{2}=0.95, \mathrm{~m}=0.90$
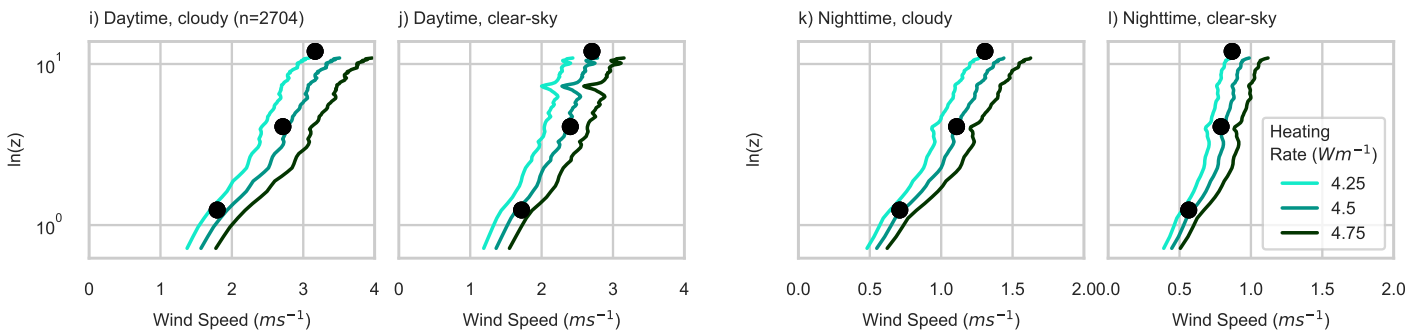

Figure 5. The heating rate of the fiber-optic cable was varied when deriving the FODS wind speed following van Ramshorts et al. van Ramshorst et al. (2020). The (a,b) bias and (c,d) sloped in FODS wind speed evaluated against the horizontal wind speed observed by the $1.25 \mathrm{~m}$ sonic anemometer. Data were stratified according to solar light and cloud regime. For the heating rate of $4 \mathrm{Wm}^{-1}$, (e-f) twodimensional histograms of the evaluation are shown. The caption indicates bias $(\mu)$, correlation coefficient $\left(r^{2}\right)$, linear slope $(m)$, and the number of minutes evaluated for each regime classification. For these same regime classifications, (i-l) vertical profiles of wind speed are shown for a varying heating rate. The dots indicate the mean horizontal wind speed observed by the sonic anemometers at $1.25 \mathrm{~m}, 4 \mathrm{~m}$, and $11.99 \mathrm{~m}$

\subsection{FlyFOX-V and the boundary layer column}

During the 18 July flight a layer of fog was present near the surface initially, but lifted to approximately $20 \mathrm{~m}$ height by $0415 \mathrm{Z}$

(e.g., Fig. 1c). The SODAR-RASS observations indicated a stronger flow above the near-surface SBL with strong wind speed and directional shear across the top of the SBL (Fig. 6b,c). In the first ten minutes wave-like patterns are seen in the tower temperature data (Fig. 6f) but the FODS wind speed suggest that the first two oscillations may not couple to the surface (Fig. $6 g)$. 
https://doi.org/10.5194/essd-2020-392

Preprint. Discussion started: 19 February 2021

(c) Author(s) 2021. CC BY 4.0 License.

(c) (i)

After $0320 \mathrm{Z}$ to $0350 \mathrm{Z}$ the wave action became more vigorous. According to the FlyFOX-V observations, the waves spanned the entire depth of the SBL (Fig. 6e) and potentially even into the residual layer where they were detected in the LIDAR data as vertical wind speeds oscillations between positive and negative values (Fig. 6a). The tower observations of temperature and wind direction also observed these waves coupling to the surface. A distinct cold air plume from near the surface is visible during the uplifting divergence phase of the wave (Fig. 6f). These tongues of deepening cold air are associated with bursts of horizontal wind speed which span the height of the tower (Fig. 6g). As the stronger flow above the SBL top lifted after 0400Z (Fig. 6c) the wave action disappeared. The tower temperatures observed the reemergence of a decoupled near-surface layer, which was consistent with the tower wind speeds observing calm conditions. FlyFOX-V observed that the top SBL decreased during this period (Fig. 6e), a feature that the SODAR-RASS was unable to capture because of the inherent volume averaging over $20 \mathrm{~m}$ deep gates.

Traditional observations are unable to resolve the vertical interactions highlighted in this simple demonstration (e.g., compare Fig. 6a,d to Fig. 6e-g). Even newer methods like drone observations would miss the wave events presented here due to the relatively long repeat time between flights (e.g., Pillar-little et al., 2020; Kral et al., 2020) and the LIDAR could only resolve the wave action when it was most vigorous and sufficiently above the surface.

Resolving the influence of waves on turbulence is a major goal of boundary layer research (Sun et al., 2015) and the FlyFOX approach is a promising avenue for achieving this goal. DTS techniques, such as FlyFOX, can connect between observations of the tower layer to observations of upper atmospheric boundary layer at an unprecedented spatial and temporal resolution, filling a gap in the observational scales of the boundary layer.

\subsection{Near-surface submeso motions}

The second example focuses on an intermittent burst of turbulence associated with a near surface, spatially-discrete submesoscale structure (Fig. 7). The extent of the submeso-scale structure is difficult to define precisely, as it is unclear which features should be considered part of the structure and which features should be associated with the background state of the boundary layer. However, the long sides of the inner and outer rectangles observed a spatially coherent, temporally transient temperature structure with a leading cold perturbation and trailing warm perturbation (Fig. 7a,b,d,f) that is approximately $80 \mathrm{~m}$ wide. Behind the warm perturbation was potentially a second, thinner cold perturbation that was more clearly resolved in the eastern components of the array. (e.g., Fig. 7b,c). Associated with the temperature structure was a maximum in horizontal wind speed along the long axis of the submeso-scale structure (Fig. 7d,e,g,h,i,l,m). This wind speed maximum was located between $1 \mathrm{~m}$ and $4 \mathrm{~m}$ above the surface (Fig. 71,m). The temperature component of the structure extended up to approximately $6 \mathrm{~m}$ agl, although this determination depends on which features are considered part of the structure as opposed to the background state.

The structure traversed the site starting in the northwest corner traveling towards the southeastern corner. At any given point the submeso-scale structure was present for approximately 2 minutes, suggesting a mean advective velocity of $0.67 \mathrm{~ms}^{-1}$ for a structure $80 \mathrm{~m}$ wide. The advective speed was slow compared to the time-averaged mean wind speed (Fig. $7 \mathrm{~m}$ ), consistent with other studies that have tracked submeso structures (Mahrt et al., 2009; Pfister et al., 2020b; Zeeman et al., 2015). 


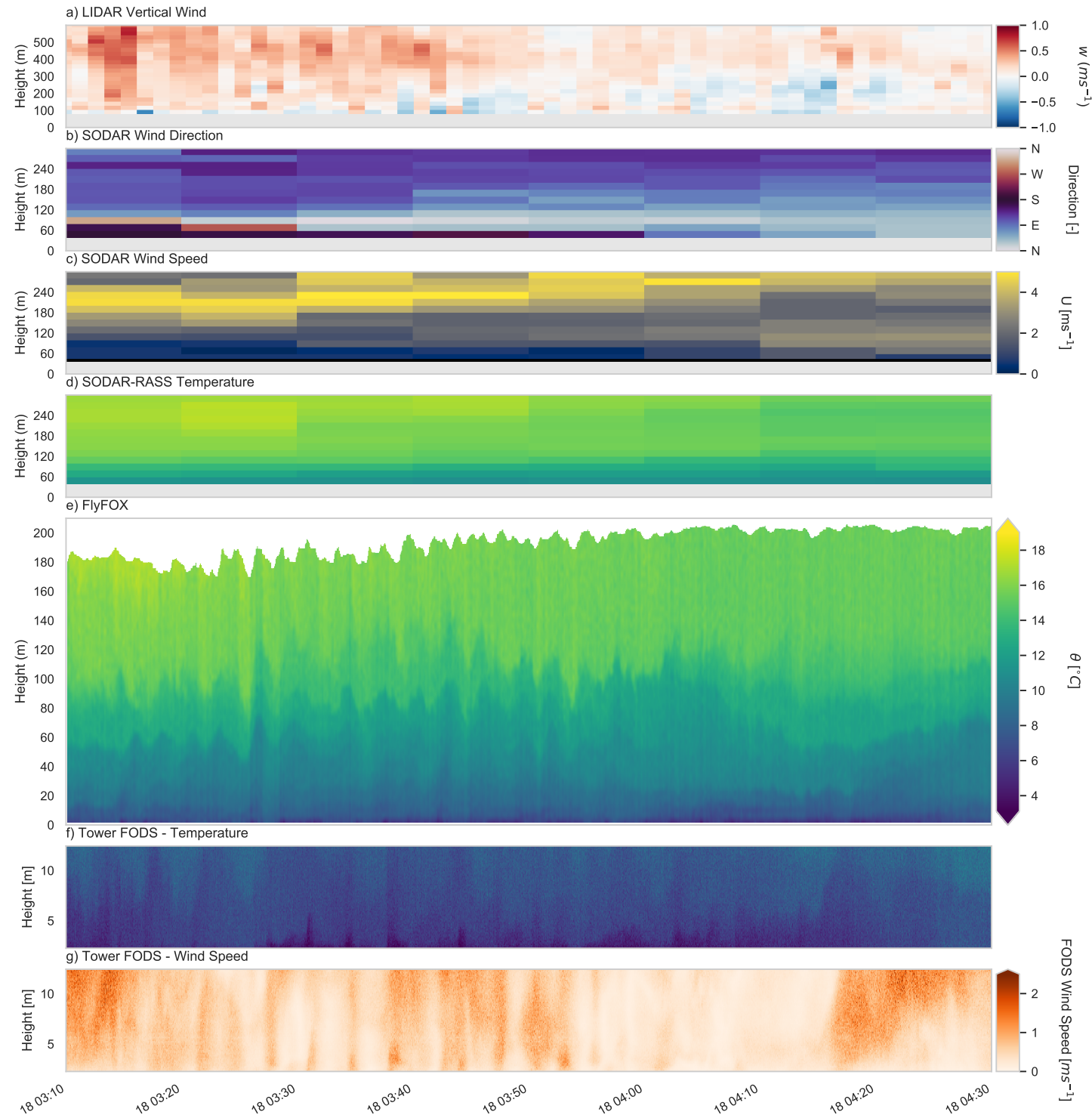

Figure 6. The LOVE19 "column" during the first FlyFOX-V on July 18 2019. (a) The LIDAR vertical stares yielded vertical wind speeds, which were aggregated to $84 \mathrm{~s}$. The SODAR derived (b) horizontal wind direction, (c) horizontal wind speed, and (d) the SODAR-RASS potential temperature during the flight. (e) The FlyFOX-V data, converted to potential temperature and height above the surface, captured complex wave structures throughout the SBL. (f) Potential temperature and (g) FODS horizontal wind speed from the $12 \mathrm{~m}$ tower track the wave structures down to the surface.

The cold portion of the submeso-scale structure interacted with the tower between 0331Z-0332Z followed by the warm portion between 0332Z-0333Z. While the cold portion of the submeso-scale structure interacted with tower, a burst of turbulence occurred and was recorded by the sonic anemometers at $0.5 \mathrm{~m}, 1.25 \mathrm{~m}$, and $4 \mathrm{~m}$. The sonic anemometer at the top of the tower 
https://doi.org/10.5194/essd-2020-392

Preprint. Discussion started: 19 February 2021

(c) Author(s) 2021. CC BY 4.0 License.

did not observe this burst of turbulence, suggesting that the effect of the submeso-scale structure on generating turbulence was constrained to near the surface, consistent with its apparent depth. Additionally, all sonic anemometers indicated a change in horizontal wind direction change creating a meandering motion as the submeso-scale structure passed the tower, with the lowest sonic anemometer leading and the higher sonic anemometers lagging increasingly with height.

Prior to the submeso-scale structure's arrival, the tower FODS observations revealed a decoupled boundary layer consistent with the hockey-stick transition concept (e.g., Sun et al., 2020) with strong static stability and decreased wind speed below $4 \mathrm{~m}$ and weak static stability and stronger wind speeds above $4 \mathrm{~m}$ (Fig. 7k,m). Simultaneously with the cold portion of the submeso-scale structure passing the tower, the wind speed accelerated between $1 \mathrm{~m}$ to $4 \mathrm{~m}$ agl, forming a distinct nose (Fig. 7o). Between $2 \mathrm{~m}$ and $4 \mathrm{~m}$ agl the stability decreased until the entire profile above $2 \mathrm{~m}$ was only weakly stable. After the passage of the submeso-scale structure, the overall wind shear within the tower layer decreased and the air across the entire profile cooled. The $4 \mathrm{~m}$ and $12 \mathrm{~m}$ sonic anemometers reported upward-directed sensible heat fluxes (Fig. 7o). While these fluxes would normally be considered non-physical, the temperature profiles from the FODS tower demonstrated that isolated and short-lived negative, i.e., unstable temperature gradients, existed during this period (Fig. 7o). This example thereby demonstrates that the FODS observations have fine enough resolution to capture rapid static stability changes and reversals that other methods cannot.

The FODS data from the LOVE19 provides a unique and powerful opportunity for exploring the nature of these types of submeso structures and their influence on boundary layer dynamics. Specifically, this example demonstrates how turbulence in the presence of submeso structures can be driven "from the side" as opposed to top-down or bottom-up factors typically assumed (e.g., Van de Wiel et al., 2017; Sun et al., 2012). Additionally, the intermittent turbulence event was explicitly not associated with classically-defined turbulent eddies. This example further highlights the importance and novelty of the distributed observations from LOVE19 for understanding submeso-turbulence interactions.

\section{Recommendations for future FODS deployments}

As there has been only one previous deployment of electrically-heated fibers in an atmospheric setting (Sayde et al., 2015), we provide some general guidelines here for future deployments, both related to heating the fiber specifically and for atmospheric DTS deployments more generally. The thin PE coating on the stainless steel fibers does not provide full electrical insulation. Unfortunately, thin PE coatings are necessary to enable the DTS to have a fast enough response time to observe turbulent perturbations (Thomas, C.K. and Selker, 2021). Consequently, special care must be taken with this technique. Even with the PE coating, a small current was induced in the reference sections that degraded the performance of the reference PT-100s, especially in our initial testing with water reference baths as employed in most DTS experiments. It is necessary to electrically isolate the heated fibers from the reference sections, for instance by cutting the fiber and performing a splice of the optical core, which has an electrical resistance many orders of magnitude larger than the conducting stainless steel sheath.

Further, as seen in Fig. 2, power failures occurred during LOVE19. These were the result of the electrically-heated fibers grounding and triggering the false current protection of the site's electrical grid. It is imperative to electrically isolate fiber 

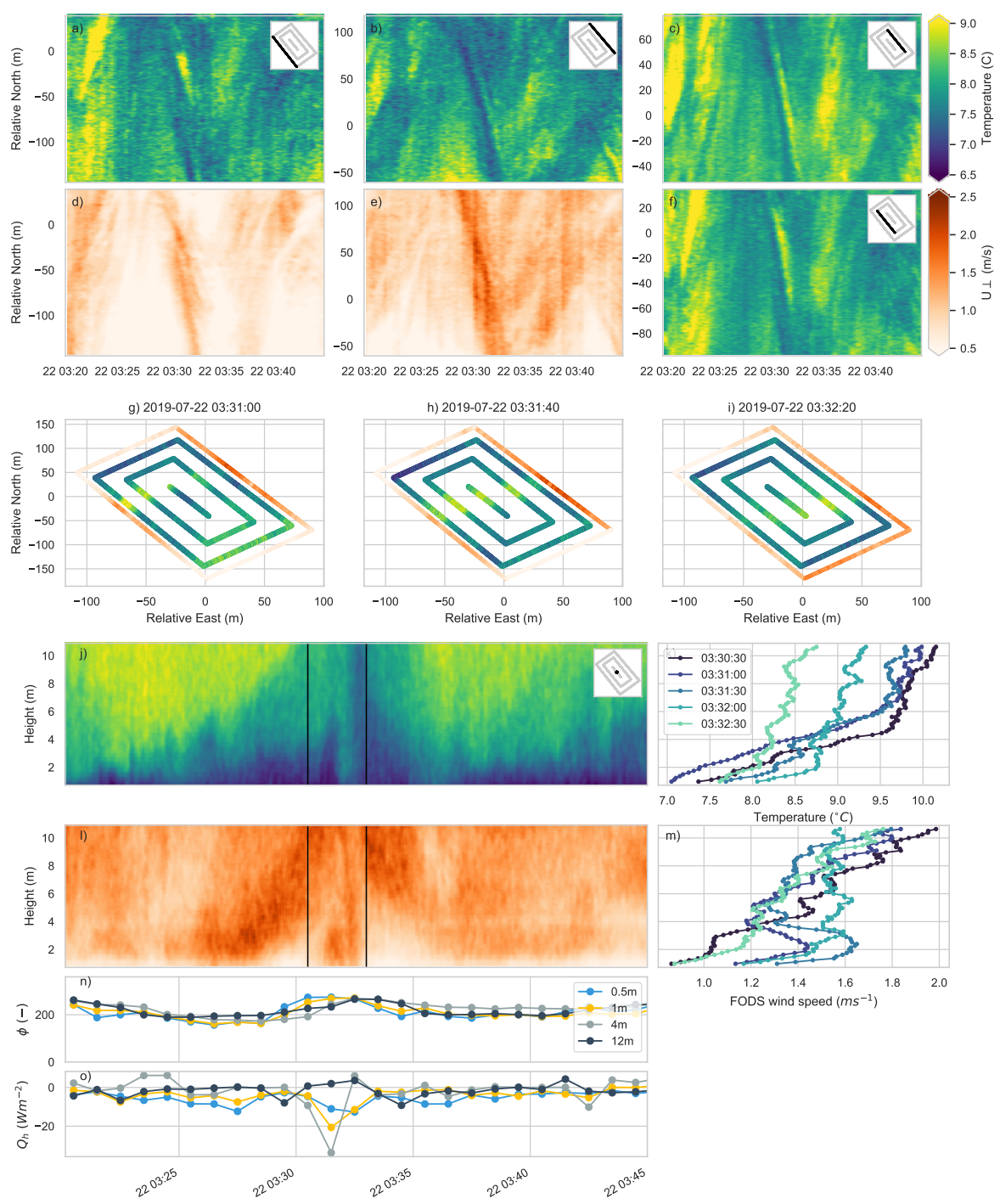

Figure 7. An example of a submeso-scale structure observed by the LOVE19 FODS array on July 22 2019. (a-c, f) DTS-observed temperatures from the outer and inner rectangle (see inset maps). (d-e) FODS wind speed along the outer rectangle. Three snapshots of the entire near-surface FODS array (g) as the leading cold portion of the submeso structure encountered the tower, (h) as the warm section encountered the tower, and (i) as the submeso structure propagated into the southeastern corner of the array. The tower observations of (j) FODS temperature and (l) FODS wind speed as the submeso structure passed the tower. The vertical lines indicate the period shown in (k, $\mathrm{m}$ ) where each line is a 30s average vertical profiles. Finally, the CSAT observations of (n) horizontal wind direction and (m) sensible heat flux are shown.

holders from ground and to keep vegetation away from the fiber. The thin PE coating, in combination with normal wear from an atmospheric deployment, made it so that power failures would occur when the wet grass contacted the heated fibers. 

validation reference sections, a problem emerged when comparing observations that should be identical, specifically the twisted pair of fibers used for the inner rectangle. Spatially-dependent biases were found (not shown) even though the bias within the reference section was small. The most likely cause was changes in the differential attenuation along the fiber e.g., caused by tension at the fiber holders (van de Giesen et al., 2012). Single-ended calibration cannot account for these changes. As a result, we recommend that all future experiments employ a double-ended setup (van de Giesen et al., 2012; des Tombe et al., 2020), but saving raw backscatter stokes and anti-stokes data from both directions separately in a single-ended fashion. These results also suggest that future DTS work may benefit from including spatially-distributed evaluation of the DTS temperatures instead of evaluating the DTS temperatures at a small number of reference sections, which are often located near the calibration reference sections. This behavior would not have been visible without the replicated temperatures from the twisted pair PVC fibers used for the inner rectangle. Additionally, even though DTS devices are capable of recording over $5 \mathrm{~km}$ of fiber length we found that noise approximately doubled with every kilometer of fiber. Future deployments should consider the trade-off between decreasing the number of temporal samples through observing multiple channels and decreasing the instrument noise through observing shorter lengths of optical core on any given channel.

In the second example, the submeso-scale structure originated from outside the study area, potentially highlighting the need for even larger DTS arrays in future experiments. Previous research on the nature of submeso-scale structures using networks of point observations suggest that they exert influence across very large spatial scales up to kilometers (Abraham and Monahan, 2020; Pfister et al., 2020a). The LOVE19 dataset should provide insights into submeso structure-turbulence interactions, but the the data may not be appropriate for studying their origins.

\section{Conclusions}

The Large-eddy Observatory - Voitsumra Experiment 2019 (LOVE19) for studying the weak-wind stable boundary layer (wwSBL) was presented. Understanding the wwSBL requires being able to separate motions on submeso scales from turbulence, as well as observations capable of resolving the spatiotemporal evolution of these motions (Mahrt and Thomas, 2016; Sun et al., 2015; Thomas, 2011; Zeeman et al., 2015; Pfister et al., 2020b, a). LOVE19 is able to fill this need by uniquely employing fiber-optic distributed sensing (FODS) of air temperature, wind speed, and wind direction. It is anticipated that LOVE19 will be of specific utility for the boundary layer community, but also more broadly for communities studying the exchange of carbon, water vapor, and energy between the atmosphere and the surface. The uniqueness of the FODS arrays, in addition to the rich supporting boundary layer observations, opens the door to addressing a wide range of research questions that could not be adequately addressed before. 
https://doi.org/10.5194/essd-2020-392

Preprint. Discussion started: 19 February 2021

(c) Author(s) 2021. CC BY 4.0 License.

(c) (1)

\section{Code and data availability}

460 All data described in this manuscript are accessible through the DOI 10.5281/zenodo.4312976, including scripts for creating Fig. 6 and 7. The python package, pyfocs, used for creating the DTS data described here is available through the DOI 10.5281/zenodo.4292491. In addition the up-to-date pyfocs package can be found on github (https://github.com/klapo/pyfocs).

Author contributions. Conceptualization: KL, AFre, CT; Methodology: KL, AFre; Software: KL, AFre; Investigation: KL (lead), AFre, AFri, JS, JO, WB, CT; Formal Analysis: KL, CT; Data Curation: KL; Writing - Original Draft: KL; Visualization: KL; Supervision: KL and CT; Project Administration: CT; Funding Acquisition: CT

Competing interests. The authors declare no competing interests

Acknowledgements. This project has received funding from the European Research Council (ERC) under the European Union's Horizon 2020 research and innovation programme (grant agreement no. 724629 DarkMix), and from the Oberfranken Stiftung. 
https://doi.org/10.5194/essd-2020-392

Preprint. Discussion started: 19 February 2021

(c) Author(s) 2021. CC BY 4.0 License.

\section{References}

Abraham, C. and Monahan, A. H.: Spatial Dependence of Stably Stratified Nocturnal Boundary-Layer Regimes in Complex Terrain, Boundary-Layer Meteorology, 177, 19-47, https://doi.org/10.1007/s10546-020-00532-x, https://doi.org/10.1007/s10546-020-00532-x, 2020.

Acevedo, O. C., Costa, F. D., Oliveira, P. E., Puhales, F. S., Degrazia, G. A., and Roberti, D. R.: The influence of submeso processes on stable boundary layer similarity relationships, Journal of the Atmospheric Sciences, 71, 207-225, https://doi.org/10.1175/JAS-D-13-0131.1, 2014.

Brantley, S. L., Goldhaber, M. B., Ragnarsdottir, K. V., and Vala Ragnarsdottir, K.: Crossing disciplines and scales to understand the critical zone, Elements, 3, 307-314, https://doi.org/10.2113/gselements.3.5.307, 2007.

Browning, K. A. and Wexler, R.: The Determination of Kinematic Properties of a Wind Field Using Doppler Radar, Journal of Applied Meteorology, 7, 105-113, https://doi.org/10.1175/1520-0450(1968)007<0105:TDOKPO>2.0.CO;2, 1968.

Cava, D., Mortarini, L., Giostra, U., Richiardone, R., and Anfossi, D.: A wavelet analysis of low-wind-speed submeso motions in a nocturnal boundary layer, Quarterly Journal of the Royal Meteorological Society, 143, 661-669, https://doi.org/10.1002/qj.2954, http://doi.wiley. com/10.1002/qj.2954, 2016.

Cava, D., Mortarini, L., Anfossi, D., and Giostra, U.: Interaction of Submeso Motions in the Antarctic Stable Boundary Layer, BoundaryLayer Meteorology, 171, 151-173, https://doi.org/10.1007/s10546-019-00426-7, https://doi.org/10.1007/s10546-019-00426-7, 2019.

des Tombe, B., Schilperoort, B., and Bakker, M.: EStimation of Temperature and Associated Uncertainty from Fiber-Optic Ramen-Spectrum Distributed Temperature Sensing, Sensors, 20, 2235-2256, https://doi.org/10.3390/s20082235, 2020.

Euser, T., Luxemburg, W. M., Everson, C. S., Mengistu, M. G., Clulow, A. D., and Bastiaanssen, W. G.: A new method to measure Bowen ratios using high-resolution vertical dry and wet bulb temperature profiles, Hydrology and Earth System Sciences, 18, 2021-2032, https://doi.org/10.5194/hess-18-2021-2014, 2014.

Fritz, A., Lapo, K., Freundorfer, A., Linhard, T., and Thomas, C. K.: Revealing the Evolution and Small-Scale Variability of the Morning Transition Phase using Distributed Temperature Sensing, Geophysical Research Letters, in review, 2020.

Hausner, M. B., Suárez, F., Glander, K. E., and Giesen, N. V. D.: Calibrating Single-Ended Fiber-Optic Raman Spectra Distributed Temperature Sensing Data, Sensors, 11, 10 859-10 879, https://doi.org/10.3390/s111110859, 2011.

Kang, Y., Belušić, D., and Smith-Miles, K.: Classes of structures in the stable atmospheric boundary layer, Quarterly Journal of the Royal Meteorological Society, 141, 2057-2069, https://doi.org/10.1002/qj.2501, 2015.

Kral, S. T., Reuder, J., Vihma, T., Suomi, I., Haualand, K. F., Urbancic, G. H., Greene, B. R., Steeneveld, G.-J., Lorenz, T., Maronga, B., Jonassen, M. O., Ajosenpää, H., Båserud, L., Chilson, P. B., Holtslag, A. A. M., Jenkins, A. D., Kouznetsov, R., Mayer, S., Pillar-Little, E. A., Rautenberg, A., Schwenkel, J., Seidl, A. W., and Wrenger, B.: The Innovative Strategies for Observations in the Arctic Atmospheric Boundary Layer Project (ISOBAR) —Unique fine-scale observations under stable and very stable conditions, Bulletin of the American Meteorological Society, pp. 1-64, https://doi.org/10.1175/bams-d-19-0212.1, 2020.

Lang, F., Beluši, D., and Siems, S.: Observations of Wind-Direction Variability in the Nocturnal Boundary Layer, Boundary-Layer Meterology, 166, 51-68, https://doi.org/10.1007/s10546-017-0296-4, 2018.

Lapo, K. and Freundorfer, A.: pyfocs v0.5, Zenodo, https://doi.org/10.5281/zenodo.4292491, https://github.com/klapo/pyfocs, 2020.

Lapo, K., Anita, F., Fritz, A., Schneider, J., Olesch, J., Babel, W., and Thomas, C. K.: Large Eddy Observatory, Voitsumra Experiment 2019 (LOVE19), Zenodo, https://doi.org/10.5281/zenodo.4312976, https://zenodo.org/record/4312976, 2020a. 
https://doi.org/10.5194/essd-2020-392

Preprint. Discussion started: 19 February 2021

(c) Author(s) 2021. CC BY 4.0 License.

Lapo, K., Freundorfer, A., Pfister, L., Schneider, J., Selker, J., and Thomas, C.: Distributed observations of wind direction using microstructures attached to actively heated fiber-optic cables, Atmospheric Measurement Techniques, 13, 1563-1573, https://doi.org/10.5194/amt13-1563-2020, 2020b.

Mahrt, L.: Variability and Maintenance of Turbulence in the Very Stable Boundary Layer, Boundary-Layer Meteorol., 135, 1-18, https://doi.org/10.1007/s10546-009-9463-6, 2010.

Mahrt, L.: Lee Mixing and Nocturnal Structure over Gentle Topography, Journal of the Atmospheric Sciences, 74, 1989-1999, https://doi.org/10.1175/JAS-D-16-0338.1, http://journals.ametsoc.org/doi/10.1175/JAS-D-16-0338.1, 2017.

Mahrt, L. and Thomas, C. K.: Surface Stress with Non-stationary Weak Winds and Stable Stratification, Boundary-Layer Meteorology, 159, 3-21, https://doi.org/10.1007/s10546-015-0111-z, 2016.

Mahrt, L., Thomas, C. K., and Prueger, J. H.: Space-time structure of mesoscale motions in the stable boundary layer, Quarterly Journal of the Royal Meteorological Society, 135, 67-75, https://doi.org/10.1002/qj.348, 2009.

Mahrt, L., Pfister, L., and Thomas, C. K.: Small-Scale Variability in the Nocturnal Boundary Layer, Boundary-Layer Meteorology, 174, 81-98, https://doi.org/10.1007/s10546-019-00476-x, https://doi.org/10.1007/s10546-019-00476-x, 2020.

Peltola, O., Lapo, K., Martinkauppi, I., Connor, E. O., Thomas, C. K., and Vesala, T.: Suitability of fiber-optic distributed temperature sensing to reveal mixing processes and higher-order moments at the forest-air interface, Atmospheric Measurement Techniques Discussions, 2020, 1-31, https://doi.org/10.5194/amt-2020-260, https://amt.copernicus.org/preprints/amt-2020-260/, 2020.

Petenko, I., Argentini, S., Casasanta, G., Genthon, C., and Kallistratova, M.: Stable Surface-Based Turbulent Layer During the Polar Winter at Dome C , Antarctica : Sodar and In Situ Observations, Boundary-Layer Meteorology, 171, 101-128, https://doi.org/10.1007/s10546018-0419-6, https://doi.org/10.1007/s10546-018-0419-610.1007/s10546-018-0419-6, 2019.

Petrides, A. C., Huff, J., Arik, A., Giesen, N. V. D., Kennedy, A. M., Thomas, C. K., and Selker, J. S.: Shade estimation over streams using distributed temperature sensing, Water Resources Research, 47, 2-5, https://doi.org/10.1029/2010WR009482, 2011.

Pfister, L., Lapo, K., Sayde, C., Selker, J., Mahrt, L., and Thomas, C. K.: Classifying the nocturnal atmospheric boundary layer into temperature and flow regimes, Quarterly Journal of the Royal Meteorological Society, 145, 1515-1534, https://doi.org/10.1002/qj.3508, 2019.

Pfister, L., Lapo, K., Mahrt, L., and Thomas, C.: Thermal Submeso-scale Motions in the Nocturnal Stable Boundary Layer - Part 2: Generating Mechanisms \& Implications, Boundary-Layer Meteorology, in press, 2020a.

Pfister, L., Lapo, K., Mahrt, L., and Thomas, C. K.: Thermal submeso-scale motions in the nocturnal stable boundary layer - Part 1: Detection \& mean statistics, Boundary-Layer Meteorology, in press, 2020b.

Pillar-little, E. A., Greene, B. R., Lappin, F. M., Bell, T. M., Segales, A. R., Britto, G., Azevedo, H. D., Doyle, W., Kanneganti, S. T., Tripp, D. D., and Chilson, P. B.: Observations of the thermodynamic and kinematic state of the atmospheric boundary layer over the San Luis Valley, CO using remotely piloted aircraft systems during the LAPSE-RATE field campaign Elizabeth, Earth System Science Data Discussions, Discussion, 1-17, https://doi.org/10.5194/essd-2020-194, 2020.

Sayde, C., Thomas, C. K., Wagner, J., and Selker, J.: High-resolution wind speed measurements using actively heated fiber optics, Geophysical Research Letters, 42, 10 064-10 073, https://doi.org/10.1002/2015GL066729.Received, 2015.

Schilperoort, B., Coenders-Gerrits, M., Luxemburg, W., Jiménez Rodríguez, C., Cisneros Vaca, C., Savenije, H., Rodríguez, C. J., Vaca, C. C., Savenije, H., Rica, T. D. C., Forestal, E. D. I., and Rica, C.: Technical note: Using distributed temperature sensing for Bowen ratio evaporation measurements, Hydrology and Earth System Sciences, 22, 819-830, https://doi.org/10.5194/hess-22-819-2018, https: //doi.org/10.5194/hess-22-819-2018, 2018. 
https://doi.org/10.5194/essd-2020-392

Preprint. Discussion started: 19 February 2021

(c) Author(s) 2021. CC BY 4.0 License.

(c) (i)

Selker, J. S., Thévenaz, L., Huwald, H., Mallet, A., Luxemburg, W., Giesen, N. V. D., Stejskal, M., Zeman, J., Westhoff, M., and Parlange, M. B.: Distributed fiber-optic temperature sensing for hydrologic systems, Water Resources Research, 42, 1-8, https://doi.org/10.1029/2006WR005326, 2006.

Sigmund, A., Pfister, L., Sayde, C., and Thomas, C. K.: Quantitative analysis of the radiation error for aerial coiled-fiber-optic distributed temperature sensing deployments using reinforcing fabric as support structure, Atmospheric Measurement Techniques, 10, 2149-2162, https://doi.org/10.5194/amt-10-2149-2017, 2017.

Sun, J., Mahrt, L., Banta, R. M., and Pichugina, Y. L.: Turbulence Regimes and Turbulence Intermittency in the Stable Boundary Layer during CASES-99, Journal of the Atmospheric Sciences, 69, 338-351, https://doi.org/10.1175/JAS-D-11-082.1, http://journals.ametsoc. org/doi/abs/10.1175/JAS-D-11-082.1, 2012.

Sun, J., Nappo, C. J., Mahrt, L., Belušic, D., Grisogono, B., Stauffer, D. R., Pulido, M., Staquet, C., Jiang, Q., Pouquet, A., Yagüe, C., Galperin, B., Smith, R. B., Finnigan, J. J., Mayor, S. D., Svensson, G., Grachev, A. A., and Neff, W. D.: Review of wave-turbulence interactions in the stable atmospheric boundary layer, Reviews of Geophysics, 53, 956-993, https://doi.org/10.1002/2015RG000487, 2015.

Sun, J., Takle, E. S., and Acevedo, O. C.: Understanding Physical Processes Represented by the Monin - Obukhov Bulk Formula for Momentum Transfer, Boundary-Layer Meteorology, 177, 69-95, https://doi.org/10.1007/s10546-020-00546-5, https://doi.org/10.1007/ s10546-020-00546-5, 2020.

Thomas, C., Mayer, J. C., Meixner, F. X., and Foken, T.: Analysis of low-frequency turbulence above tall vegetation using a Doppler sodar, Boundary-Layer Meteorology, 119, 563-587, https://doi.org/10.1007/s10546-005-9038-0, 2006.

Thomas, C. K.: Variability of Sub-Canopy Flow, Temperature, and Horizontal Advection in Moderately Complex Terrain, Boundary Layer Meteorology, 139, 61-81, https://doi.org/10.1007/s10546-010-9578-9, 2011.

Thomas, C. K., Law, B. E., Irvine, J., Martin, J. G., Pettijohn, J. C., and Davis, K. J.: Seasonal hydrology explains interannual and seasonal variation in carbon and water exchange in a semiarid mature ponderosa pine forest in central Oregon, Journal of Geophysical Research, 114, G04 006, https://doi.org/10.1029/2009JG001010, 2009.

Thomas, C. K., Kennedy, A. M., Selker, J. S., Moretti, A., Schroth, M. H., Smoot, A. R., Tufillaro, N. B., and Zeeman, M. J.: High-resolution fibre-optic temperature sensing: A new tool to study the two-dimensional structure of atmospheric surface layer flow, Boundary-Layer Meteorology, 142, 177-192, https://doi.org/10.1007/s10546-011-9672-7, 2012.

Thomas, C.K. and Selker, J.: Optical fiber-based distributed sensing methods, in: Handbook of Atmospheric Measurements, chap. Chapter 20, p. Springer International Publishing, 2021.

Tyler, S. W., Selker, J. S., Hausner, M. B., Hatch, C. E., Torgersen, T., Thodal, C. E., and Schladow, S. G.: Environmental temperature sensing using Raman spectra DTS fiber-optic methods, Water Resources Research, 45, 1-11, https://doi.org/10.1029/2008WR007052, 2009.

van de Giesen, N., Steele-Dunne, S. C., Jansen, J., Hoes, O., Hausner, M. B., Tyler, S., and Selker, J.: Double-ended calibration of fiber-optic raman spectra distributed temperature sensing data, Sensors (Switzerland), 12, 5471-5485, https://doi.org/10.3390/s120505471, 2012.

575 Van de Wiel, B. J. H., Vignon, E., Baas, P., van Hooijdonk, I. G. S., Van der Linden, Steven, J. A., van Hooft, J. A., Bosveld, F. C., de Roode, S. R., Moene, A. F., Genthon, C., van der Linden, S. J. A., van Hooft, J. A., Bosveld, F. C., de Roode, S. R., Moene, A. F., and Genthon, C.: Regime Transitions in Near-Surface Temperature Inversions: A Conceptual Model, Journal of the Atmospheric Sciences, 74, 1057-1073, https://doi.org/10.1175/JAS-D-16-0180.1, 2017. 
https://doi.org/10.5194/essd-2020-392

Preprint. Discussion started: 19 February 2021

(C) Author(s) 2021. CC BY 4.0 License.

(c) (1)

van Ramshorst, J. G. V., Coenders-Gerrits, M., Schilperoort, B., van de Wiel, B. J. H., Izett, J. G., Selker, J. S., Higgins, C. W., Savenije, H.

H. G., and van de Giesen, N. C.: Revisiting wind speed measurements using actively heated fiber optics : a wind tunnel study, Atmospheric Measurement Techniques, 13, 5423-5439, https://doi.org/10.5194/amt-13-5423-2020, 2020.

Wilczak, J. M., Oncley, S. P., and Stage, S. A.: Sonic anemometer tilt correction algorithms, Boundary-Layer Meteorology, 99, 127-150, https://doi.org/10.1023/A:1018966204465, 2001.

Zeeman, M. J., Selker, J. S., and Thomas, C. K.: Near-Surface Motion in the Nocturnal , Stable Boundary Layer Observed with Fibre-Optic 